\title{
CARACTERÍSTICAS EMPREENDEDORAS DO FUTURO ENFERMEIRO
}

Gímerson Erick Ferreira' ${ }^{1}$ Célia Alves Rozendo², Regina Maria dos Santos ${ }^{3}$, Eduardo Araújo Pinto ${ }^{4}$, Antonio Carlos Silva Costa ${ }^{5}$, Adrize Rutz Porto ${ }^{6}$

\begin{abstract}
RESUMO: Este estudo teve por objetivo conhecer as características empreendedoras do graduando em enfermagem. Trata-se de uma pesquisa qualitativa desenvolvida de setembro a outubro de 2011 em uma universidade pública do Nordeste brasileiro com 15 formandos; os preceitos éticos foram observados. Os dados foram coletados por meio de entrevistas semiestruturadas e tratados por análise temática, resultando em quatro categorias que delimitam as características empreendedoras: busca por oportunidades não exploradas, orientação para o futuro, necessidade de auto realização e articulação estratégica. As características empreendedoras exprimem o desejo de futuros enfermeiros em contribuir com o desenvolvimento social a partir de suas práticas, investindo em atitudes proativas e detectando oportunidades diferenciadas de cuidar, a partir de modos de agir que os permitam inovar ao vislumbrarem o exercício da profissão.
\end{abstract}

DESCRITORES: Estudantes de enfermagem; Gestão em saúde; Enfermagem; Competência profissional.

\section{BUSINESS CHARACTERISTICS OF THE FUTURE NURSE}

ABSTRACT: This study aimed to investigate the business characteristics of the nursing student. This is qualitative research undertaken between September and October 2011 in a state university of the Brazilian Northeast, with 15 students; the ethical precepts were observed. The data was collected through semi-structured interviews and was treated with thematic analysis, resulting in four categories which delimit the business characteristics: seeking unexplored opportunities, guidance for the future, need for self-realization and strategic articulation. The business characteristics express the desire of future nurses to contribute to social development through their practices, investing in proactive stances and detecting differentiated opportunities for caring, based on ways of acting which allow them to innovate in detecting the exercising of the profession. DESCRIPTORS: Student nurses; Health management; Nursing; Professional competence.

\section{CARACTERÍSTICAS EMPRENDEDORAS DEL FUTURO ENFERMERO}

RESUMEN: Este estudio tuvo el objetivo de conocer las características emprendedoras del graduando en enfermería. Es una investigación cualitativa desarrollada de septiembre a octubre de 2011 en una universidad pública de la Región Nordeste de Brasil con 15 estudiantes que van a formarse; los preceptos éticos fueron observados. Los datos fueron obtenidos por medio de entrevistas semiestructuradas y pasaron por análisis temático, resultando en cuatro categorías que delimitan las características emprendedoras: búsqueda por oportunidades no exploradas; orientación para el futuro; necesidad de autorrealización; y articulación estratégica. Las características emprendedoras exprimen el deseo de futuros enfermeros en contribuir con el desarrollo social a partir de sus prácticas, invirtiendo en actitudes proactivas y detectando oportunidades distintas de cuidar, con base en los modos de actuar que los permitan innovar al vislumbrar el ejercicio de la profesión.

DESCRIPTORES: Estudiantes de enfermería; Gestión en salud; Enfermería; Competencia profesional.

\footnotetext{
${ }^{1}$ Enfermeiro e Administrador. Mestrando pelo Programa de Pós-Graduação em Enfermagem da Universidade Federal do Rio Grande do Sul - PPGENF UFRGS. Membro do Núcleo de Estudos sobre Gestão em Enfermagem - NEGE, e do Grupo de Pesquisa Empreendedorismo, Geração de Negócios e Turismo.

${ }^{2}$ Enfermeira. Doutora em Enfermagem. Professora da Escola de Enfermagem e Farmácia - ESENFAR, Coordenadora do Programa de Pós-Graduação em Enfermagem da Universidade Federal de Alagoas - PPGENF UFAL. Líder do Grupo de Estudos e Pesquisas Cuidado em Saúde, e membro do Grupo Saúde Coletiva e Ensino na Saúde.

${ }^{3}$ Enfermeira. Doutora em Enfermagem. Professora da ESENFAR e do PPGENF UFAL. Líder do Grupo de Estudo D. Isabel Macintyre - GEDIM, e do PROCUIDADO.

${ }^{4}$ Enfermeiro. Mestrando pelo PPGENF UFAL. Membro do GEDIM e PROCUIDADO.

${ }^{5}$ Cientista Social. Doutor em Psicologia Experimental. Professor da Faculdade de Economia, Administração e Contabilidade - FEAC e do Programa de Pós-Graduação em Ensino na Saúde da UFAL. Líder do Grupo de Pesquisa Empreendedorismo, geração de negócios e Turismo.

${ }^{6}$ Enfermeira. Doutoranda em Enfermagem pelo PPGENF UFRGS. Membro do NEGE.
} 


\section{INTRODUÇÃO}

O mundo do trabalho é governado por normas que passam por modificações constantes, decorrentes da agilidade da vida contemporânea, cerceada por transformações tecnológicas e influenciada por paradigmas capitalistas e pela repercussão destes nas relações sociais ${ }^{(1)}$. Na área da enfermagem essa realidade não é diferente, sendo demandadas de seus trabalhadores características cada vez mais diferenciadas. Desse modo, o diferencial de um profissional não está mais apenas em suas habilidades, currículo, formação ou experiência, mas também no modo como se comporta, percebe o mundo, visualiza as oportunidades, relaciona-se e é capaz de inovar, de (re)criar e de se (re)inventar ${ }^{(2)}$. Nesse sentido, o perfil empreendedor condiz com a conduta ativa do profissional em desvencilhar-se de condutas retrógradas oriundas da limitação de pensamentos e ações, em captar deficiências não solucionadas em suas áreas, criar técnicas eficientes e efetivas ou utilizar as já existentes de forma inovadora ${ }^{(3)}$. Profissionais com atitudes empreendedoras de intervenção social induzem o desenvolvimento de um saber complexo, capaz de levar em conta as variáveis múltiplas do processo saúde e doença ${ }^{(4)}$.

Cabe mencionar que o empreendedorismo não se trata de uma ciência e, por isso, não possui uma única definição. Fundamentado neste preceito, buscou-se por meio deste estudo, explorar uma perspectiva norteada pela visão social do empreendedorismo para além da incansável busca pelo lucro e competitividade de mercado, a qual seja capaz de promover a excelência na gestão com enfoque no cuidado complexo em saúde, mediante ações e estratégias também de cunho social.

Assim, ser empreendedor significa ter a necessidade de realizar coisas novas e, ao mesmo tempo, pôr em prática ideias já existentes, de forma inovadora, visando a solução de problemas. Empreender é criar e construir algo de valor a partir de praticamente nada, ou seja, envolve a definição, criação e distribuição de valor e benefícios para indivíduos, grupos, organização e sociedade, estando a capacidade empreendedora na capacidade de perceber o que nenhum outro viu, atribuindo ações promissoras ${ }^{(2)}$. Tais características, muitas vezes, são difíceis de ser encontradas nos profissionais enfermeiros, sendo necessário investir na formação destes adotando metodologias que fujam ao modelo convencional ${ }^{(5)}$.

Logo, faz-se imprescindível rever os aspectos que delineiam a formação destes profissionais a partir de suas características, pois do contrário, estaremos presenciando com tristeza os bons estudantes e os melhores profissionais fracassarem por não desenvolver habilidades para entender o mundo que existe além do mercado. Isto porque, mais importante que saber fazer, é criar o que fazer, aprendendo a lidar com a complexidade.

Diante de tal aspecto e da escassez de pesquisas acerca desse tema na Enfermagem em busca realizada pelos pesquisadores na base de dados BDENF e Literatura Latino-Americana e do Caribe em Ciências da Saúde (LILACS), este estudo teve por objetivo conhecer as características empreendedoras do formando de enfermagem. Por meio do discurso do futuro enfermeiro, buscou-se visualizar traços que delinearam o perfil empreendedor, podendo contribuir com conhecimentos geradores de atitudes proativas para cuidar de modo integral e resolutivo.

\section{MÉTODO}

Estudo exploratório e descritivo, com abordagem qualitativa, realizado em uma universidade pública de Maceió - Alagoas. A escolha dos participantes da pesquisa foi intencional, contando com 15 acadêmicos de enfermagem dos 60 que estavam no último ano do curso no período de realização do estudo (setembro e outubro de 2011). Foram critérios de inclusão: estar matriculado no último ano, cursando um dos estágios supervisionados obrigatórios, por apresentar, provavelmente, mais maturidade ao refletir sobre as características adquiridas e,consequentemente, possuir mais elementos que contribuam com a pesquisa. O número de participantes foi definido a partir do critério de saturação dos dados.

Os dados foram coletados por meio de entrevista semiestruturada, com questionamentos acerca das vivências e perspectivas dos formandos relacionadas à prática de enfermagem, que permitissem captar características empreendedoras. Os entrevistados tiveram suas falas gravadas e transcritas, constituindo o corpus do estudo. Optou-se por denominar os informantes pela letra $\mathrm{F}$ (formando) seguida do número sequencial da realização das entrevistas.

Para análise dos dados foi utilizada a técnica de análise de conteúdo por tratar-se de procedimento que parte da mensagem e possibilita a compreensão dos significados ${ }^{(6)}$. Optou-se pela análise temática, cuja técnica visa desmembrar o texto em unidades e categorias, realizando a interpretação e análise das características empreendedoras encontradas nas falas dos entrevistados. Foram obtidas 96 unidades de regis- 
tro, organizadas em 19 subcategorias e trabalhadas em quatro categorias intituladas: busca por oportunidades não exploradas, orientação para o futuro, necessidade de autorrealização e articulação estratégica.

Os critérios éticos para pesquisas que envolvem seres humanos foram respeitados ${ }^{(7)}$, sendo o projeto aprovado pelo Comitê de Ética em Pesquisa da instituição em que foi realizado o estudo, sob parecer n. 020117/2010-31. A participação na pesquisa foi voluntária e condicionada à assinatura do Termo de Consentimento Livre e Esclarecido.

\section{RESULTADOS}

Dos formandos entrevistados, três eram do sexo masculino, os demais do feminino, com idade entre 20 e 29 anos. A partir da análise dos dados foram construídas as categorias apresentadas a seguir.

\section{Busca por oportunidades não exploradas}

Para os formandos, o enfermeiro que vai ingressar no mercado de trabalho precisa mostrar que dispõe de senso de oportunidade, estar atento ao que acontece à sua volta, e buscar novas oportunidades, ser capaz de aproveitar situações incomuns em sua prática e que possibilitem iniciar atividades diferenciadas, como extratos das falas:

Hoje tenho um novo olhar, sinto que sou capaz de identificar melhor as oportunidades que surgem, e que me permitem atuar da melhor forma. (F3)

Especialmente o aluno que está prestes a ingressar no mercado, ele vive em estado de alerta para qualquer oportunidade que possa surgir. (F8)

Quando lido com um paciente, percebo a necessidade dele, é preciso estar atento não só ao que ele fala, mas ao que ele precisa naquele momento e como posso satisfazê-lo. (F11)

Os participantes verbalizaram, constantemente, o desejo de buscar oportunidades não exploradas, e que denotam uma postura empreendedora ao agir com iniciativa e proatividade ante as situações. Além disso, relataram persistência na consecução de seus objetivos, busca de informações sobre o que lhes é pertinente na circunstância vivenciada, característica que os permitem se antecipar aos fatos, propondo soluções inovadoras:
Eu vou buscar, vou atrás, "corro", procuro coisas novas, inovações, coisas diferentes do que as pessoas fazem, [...] não costumo esperar que me peçam para fazer, vou lá e faço! (F3)

Pelo que percebi e vivi na Atenção Básica, a gente tem mais espaço [...] mais autonomia, mais liberdade, e assim você consegue inovar, inventar, criar, e acaba dando certo. (F10)

É bom quando a gente tem essa liberdade de fazer, de criar alguma coisa que a gente acha que vai dar certo. [...] de intervir de maneira diferente. (F13)

A nossa formação instigou essa sede por buscar conhecer melhor as coisas, então, quando vou para campo, procuro saber o máximo sobre a realidade daquele lugar. (F15)

As falas expressam que os futuros enfermeiros, neste estudo, dispõem de senso de oportunidade, na medida em que se mostram atentos ao que acontece à sua volta, e, a partir disto, conseguem identificar melhor as necessidades das pessoas e da comunidade, sendo capazes de aproveitar situações incomuns para agir proativamente.

\section{Orientação para o futuro}

Observou-se que os formandos demonstram disponibilidade para planejar suas atividades definindo objetivos, na medida em que sabem onde querem chegar e detalham os passos que devem seguir. As falas demonstram determinação, senso de direção e estabelecimento de metas que tenham significado pessoal para estes sujeitos. Os futuros enfermeiros verbalizaram o gosto por objetivos e metas para se sentirem desafiados, como pode ser verificado a seguir:

O curso de enfermagem me ensinou a planejar mais detalhadamente as minhas ações, então, para tudo na vida, hoje, eu defino onde quero chegar e planejo cada etapa para aquilo. (F7)

Eu consigo visualizar claramente os meus objetivos para, pelo menos uns três anos depois que eu me formar. Claro que nunca se sabe, mas é sempre bom ter um plano B. (F11)

Agora o meu foco é concursos, tenho bem claro isso para mim, já planejei viagens, vou viajar para vários 
lugares para fazer as provas, mas isso me faz querer ainda mais! (F12)

Para os futuros enfermeiros, é preciso ter o domínio de suas ações, sabendo acompanhar a execução dos planos. Os participantes reconheceram o cenário de mudanças com os quais se deparam na contemporaneidade, e estão atentos à necessidade de realização de mudanças e adaptações, sempre que se fizer necessário. Isso fica evidenciado nas falas:

A vida é muito dinâmica, e a gente precisa acompanhála, buscar sempre mais, ter ânsia de aprender, então é preciso planejar bem as coisas, embora saiba que tudo pode mudar. (F1)

Muitas vezes a gente chega no serviço com uma ideia, uma perspectiva, mas é preciso se adaptar àquela realidade. $(\mathrm{F} 7)$

As mudanças hoje ocorrem num piscar de olhos, então, se eu não tenho domínio das minhas ações, acabo me perdendo. (F9)

Tais afirmações mostram que a orientação para o futuro faz parte do momento de vida destes estudantes. Ansiosos pelo futuro que os espera após sua formação, exprimem uma forte e positiva orientação para o crescimento na carreira, elaboram planos e metas e acompanham as suas consecuções, realizando mudanças e adaptações quando necessário.

\section{Necessidade de autorrealização e de excelência no que faz}

Os futuros enfermeiros sentem necessidade permanente de projetar, criar e realizar coisas novas, adotando isto como um desafio pessoal. São autoconfiantes na medida em que buscam maior autonomia em relação ao controle das suas vidas, creem em si próprios e confiam no que fazem, ou no que são capazes e podem fazer, assumindo responsabilidade pessoal pelo seu desempenho pessoal, como exemplificado nos seguintes depoimentos:

A gente sai com aquela ideia de que vai mudar o mundo, que vai fazer diferente... Então, é muito difícil não pensar em exercer a profissão da forma mais positiva possivel [...] quero muito ser um bom enfermeiro, capaz de transformar a realidade do serviço. (F15)
Eu sei que depende mais de mim e que as chances de dar certo ou errado, são provocadas pelas decisões que eu tomo. (F7)

Hoje nada me deixa tão bem, tão realizada, quanto a sensação de poder ajudar alguém e de ser reconhecida, de ser boa naquilo que faço. (F5)

Ao mesmo tempo, eles emonstraram o desejo de fazer as coisas de maneira correta, encontrando modos para fazer melhor e mais rapidamente, sendo capazes de se adaptar ao ambiente, de agir proativamente e de buscar, constantemente, novos desafios, como exemplificado nos depoimentos:

Nesta fase do curso a gente fica sedenta por fazer sempre mais e melhor, por ser mais rápida, mais eficiente, mais proativa, mais crítica [...]. E é algo que quero levar para a vida! (F4)

Como fiz muitos na rede privada [estágios curriculares não-obrigatórios] meio que absorvi isto de evitar desperdício, ser mais ágil. A gente acaba se adaptando pra fazer melhor. (F8)

Não consigo ficar satisfeita com pouco, eu quero sempre almejar, alcançar melhores resultados, quero sempre mais! E quero que essa superação continue, aceitando os desafios que vierem daqui pra frente. (F1)

\section{Articulação estratégica}

Apesar de ressaltarem a dificuldade de trabalhar com diferentes profissionais, os formandos acreditam terem desenvolvido habilidades para lidar com pessoas, para convencer e motivá-las, estimulando-as e usando palavras e ações adequadas, como depoimentos a seguir:

A gente acaba se tornando mais convincente [...]. $O$ enfermeiro precisa conquistar o paciente, convencêlo [...] os auxiliares e técnicos precisam trabalhar de modo grupal. (F5)

Creio que o desafio maior da profissão é relacional, lidar com uma equipe multiprofissional, várias cabeças, diferentes perspectivas; mas estou pronta para isso! (F13)

O modo como eu ajo perante o grupo, mostra muito de mim, então eu sei que preciso saber lidar com 
pessoas, motivá-las, tratá-las bem, e isso é tanto a equipe como com a comunidade, eu tenho que saber lidar com ela, falar a lingua dela, agir conforme as expectativas. (F12)

Procuro manter uma boa rede de relacionamentos com a equipe, os usuários, os familiares, e até mesmo com pessoas que exerçam influência no serviço e que possam trazer algum beneficio, como gestores, políticos, secretaria de saúde. Acho que isso faz parte também. (F9)

Essa consciência de que é preciso lidar com pessoas, desperta nos formandos a necessidade de adotar uma articulação estratégica com a equipe, usuários, comunidade, gestores e entidades, demonstrando que os futuros profissionais são capazes de criar uma rede de relações propositiva, sendo persuasivos e pondo-se em contato com pessoas-chaves que possam auxiliar no alcance de seus objetivos.

\section{DISCUSSÃO}

A partir deste estudo, buscou-se explorar uma perspectiva social do empreendedorismo capaz de estimular a excelência na gestão do cuidado em enfermagem.

Contudo, a contemporaneidade tem sido marcada por profundas e radicais mudanças decorrentes do impacto da globalização na vida das pessoas dentro e fora do ambiente de trabalho. Isso tem demandado um trabalhador, autônomo, flexível e proativo, capaz de assumir integralmente a responsabilidade por sua atividade, bem como por suas possíveis falhas ${ }^{(1,8)}$. Nesse cenário, a introdução de novos modelos gerenciais tem modificado a forma como realizamos o trabalho, cabendo ao profissional contemporâneo o desafio de acompanhar e adaptar-se, o que pode ser preocupante. Isto porque o sujeito passa a viver uma constante luta, numa correria interminável para manter-se no mesmo lugar ${ }^{(1)}$.

Neste âmbito, o empreendedorismo perde o seu valor (ou assume o valor tão cultuado na sociedade contemporânea), não estando mais ligado à qualidade da obra, do objeto de trabalho realizado, da atividade desenvolvida; e passa a se inscrever na adesão a um sistema de pensamento, crenças e princípios que precisam ser interiorizados.

Esta realidade não deve ser condizente à enfermagem, pois, apesar de ser compreendida como uma profissão dinâmica, inovadora e aberta às transformações sociais, está, acima de tudo, inserida num processo de trabalho que produz serviços em saúde e cujo objeto é o cuidado ${ }^{(9)}$. Desse modo, o grande desafio de empreender em enfermagem está em compreender e cuidar do ser humano como um ser integral e integrador ${ }^{(10)}$.

Assim, ponderando que as constantes mudanças do mundo do trabalho refletem não só no desenvolvimento das práticas profissionais do enfermeiro, como também em sua formação, visualizou-se no futuro enfermeiro, a oportunidade de identificar características que anunciassem o instinto de empreender, para além dos limites institucionalizados e da mobilização subjetiva típica do caráter que o trabalho assume na contemporaneidade. Nessa perspectiva, buscou-se nas falas elementos que ilustrassem o futuro enfermeiro como um empreendedor, ou conforme anunciado na literatura, um profissional preocupado em compreender a problemática local e com a necessidade de inserir-se ativamente em política públicas voltadas para as demandas sociais ${ }^{(4)}$.

Foram visualizadas nos futuros enfermeiros características que exprimem a iniciativa, persistência e busca de informações ante as situações deparadas. Tais características demonstram a necessidade destes em buscar oportunidades ainda não exploradas, vislumbrando a antecipação dos fatos para propor situações inovadoras em suas atividades.

A oportunidade empreendedora surge a partir da existência de uma circunstância favorável e adequada para agir, criando diferenciais naquilo que o indivíduo faz e acredita ser apropriado ao alcance de seus objetivos $^{(11)}$. Nesse sentido, a busca por oportunidade relatada pelos formandos ocorre tanto no sentido de almejar novas perspectivas para a profissão que futuramente irão abraçar, e que os levem a serem bons profissionais, como para construir sua carreira e ingressar no mercado de trabalho. Buscar oportunidades em enfermagem permite pensar os processos a partir da certeza de que as ações de cuidado em saúde, ensinadas aos futuros profissionais, precisam incluir valores, desejos e compromissos com o cuidado e com o conhecimento, se considerado que o ato de cuidar do outro requer dimensões amplas e abrangentes ${ }^{(12)}$.

Outras características visualizadas nos formandos, típicas do perfil empreendedor, situam-se na necessidade de estar orientado para o futuro. Os participantes mostraram-se orientados para a realização de seus desejos, e aptos a desenvolver a visão de longo de prazo, mediante definição dos seus objetivos e metas e domínio de suas ações. Caracteristicamente, pessoas empreendedoras não apenas definem situações, mas também imaginam visões sobre o que desejam alcan- 
çar, sempre imaginando e definindo o que querem fazer e como irão fazê-lo ${ }^{(13)}$.

Destarte, os acadêmicos devem estar orientados para o futuro, aptos a tomar iniciativa, gerenciando a força de trabalho, recursos físicos e materiais e de informação, utilizando como competência estratégica, o planejamento e o acompanhamento de suas metas, garantindo assim, uma assistência de qualidade ${ }^{(14)}$. $\mathrm{O}$ estudo sugere que os futuros enfermeiros, na busca por excelência em suas ações, procuram informações que os ajudem a desempenhar melhor suas ações, tendo no planejamento um guia para o que vão fazer, como irão fazer, e redefinindo as ações sempre que necessário.

A busca por autorrealização e excelência no que faz, também se mostrou algo significativo para estes. Os formandos expressaram o desejo de projetar, criar e realizar coisas novas, adotando isto como algo que de fato querem conquistar, um desafio pessoal. Percebeuse que os futuros enfermeiros estavam instigados por querer fazer as coisas melhor, por serem proativos. Numa perspectiva empreendedora, o acadêmico guiase por uma nova concepção de mundo, de sociedade e de ser humano, acreditando na possibilidade de ampliação do cuidado e na exploração de novos espaços de atuação profissional ${ }^{(15)}$. Compreende-se que o desafio de empreender em enfermagem pode estar ligado ao despertar das instituições de ensino, uma vez que cabe a estas o anseio de investir na (trans) formação de seus alunos e de incentivar a prática de empreender socialmente nos espaços de aprendizagem, por meio de ferramentas que possibilitem a criação de oportunidades de mudança social ${ }^{(16)}$.

É preciso desenvolver a formação no sentido de potencializar as qualidades e problematizar situações díspares na realidade que o indivíduo está inserido, instigando-o a buscar soluções e novas possibilidades de intervenção social, pelo desenvolvimento de práticas proativas e comprometidas com a transformação de realidades $^{(15)}$. Sob este aspecto, os formandos verbalizaram o desejo de encontrar, e conseguir operacionalizar, formas de desenvolver suas ações de modo proativo.

A última categoria explanada versou sobre características voltadas à articulação estratégica. Nesse aspecto, foram denotadas características importantes, como a habilidade de persuasão e a construção de rede de relações que os permitam alcançar propósitos. A possibilidade de construir novas relações, novas chances, novas responsabilidades, constitui-se um desafio pessoal que serve de modelo para ser vivido e partilhado ${ }^{(16)}$.

À vista disso, os futuros profissionais precisam adquirir competências diferenciadas, não tecnicistas, voltadas à produção de conhecimento interativo e que os tornem trabalhadores dotados de uma visão sensível, analítica e intuitiva, prontos para propor ações organizacionais coletivas, multiplicando oportunidades de desenvolvimento e cidadania ${ }^{(16)}$. O relacionamento interpessoal com a equipe é visto como necessário ao profissional contemporâneo, visto que o habilita a lidar de forma eficaz com pessoas, facilitando as relações do dia a dia no contexto institucional e tornando suas atitudes mais efetivas, garantindo um trabalho harmonioso ${ }^{(14)}$.

Em meio aos resultados encontrados neste estudo, atenta-se ao fato de que o futuro enfermeiro, apesar de possuir características empreendedoras, deve estar preparado para interpretar o caráter que o trabalho assume na contemporaneidade, visualizando-o em seus aspectos mais singulares, lendo-o nas entrelinhas, pois, mais que estar atento às exigências do mercado de trabalho, precisa estar ciente do seu papel junto à sociedade.

É preciso estar atento à (re)produção de discursos sob a lógica corporativista, a qual estimula a ideia de empreendedorismo como objeto de engajamento subjetivo do sujeito, assegurando que cada indivíduo assuma, como suas, as metas de reprodução do sistema capitalista $^{(1,8,17)}$. E, deste modo, termine por se distanciar da busca pela emancipação, ao tempo em que promove modelos opressivos de comportamentos individuais destinados a trabalhar ideologicamente para o alcance dos objetivos do capital ${ }^{(17)}$. Nesse sentido, reconhece-se a necessidade de estimular o sistema formador a transformar-se na direção de um ensino que, dentre outras características, valorize o rompimento de estruturas cristalizadas e modelos convencionais de ensino. E de modo a formar profissionais de saúde com competências que lhe permitam o desenvolvimento de práticas sociais proativas e comprometidas não mais com o mercado, mas com o indivíduo, o coletivo e a transformação social.

\section{CONCLUSÃo}

O estudo possibilitou identificar traços notadamente empreendedores nas falas dos futuros enfermeiros que reconheceram a necessidade de agir de modo diferenciado frente à possibilidade de ingresso no mercado de trabalho, ou nas situações já vivenciadas. Esses reconheceram ser necessário romper com práticas do enfermeiro subordinado, tarefeiro e que se limita a operar em sua zona de conforto. Em suma, a pesquisa apontou características empreendedoras nos acadêmicos de enfermagem, como determinação, 
necessidade permanente de projetar, criar e realizar atividades proativamente, habilidades para lidar com pessoas e para motivá-las.

Os aspectos levantados pelo estudo mostraram-se necessários, pois tangenciaram um processo de avaliação da formação, ao buscar nos formandos traços empreendedores que provavelmente estiveram presentes, de alguma forma, nos conteúdos e experiências do curso em conclusão. No entanto, um limite do estudo é o baixo número de participantes, logo, fazem-se necessárias pesquisas com um olhar mais atento e propositivo para a formação destes profissionais, no sentido de possibilitar aprendizados voltados à esfera social, capaz de estimular o desejo de empreender e de fomentar atitudes proativas.

Perceber-se como um profissional empreendedor, elaborando condições de trabalho criativas, autônomas e voltadas à resolubilidade de problemas sociais, éalmejado pelo futuro enfermeiro, mesmo que de modo incipiente.

\section{REFERÊNCIAS}

1. Bauman Z. Vida líquida. $2^{\mathrm{a}}$ ed. Rio de Janeiro: Jorge Zahar; 2009.

2. Dolabela, F. Oficina do empreendedor. Rio de Janeiro: Sextante; 2008.

3. Erdmann AL, Fernandes JV, Melo C, Carvalho BR, Menezes Q, Freitas R, et al. A visibilidade da profissão de enfermeiro: reconhecendo conquistas e lacunas. Rev. bras. enferm. [Internet] 2009;62(4) [acesso em 29 out 2013]. Disponível: http://dx.doi.org/10.1590/S003471672009000400025

4. Backes DS, Erdmann AL, Büscher A. O cuidado de enfermagem como prática empreendedora: oportunidades e possibilidades. Acta Paul. Enferm. [Internet] 2010;23(3) [acesso em 29 out 2013]. Disponível: http://dx.doi.org/10.1590/S0103-21002010000300005

5. Roncon PF, Munhoz S. Estudantes de enfermagem têm perfil empreendedor? Rev. bras. enferm. [Internet] 2009;62(5) [acesso em 29 out 2013]. Disponível: http:// dx.doi.org/10.1590/S0034-71672009000500007

6. Bardin L. Análise de conteúdo. Lisboa: Edições 70; 2009.

7. Ministério da Saúde(BR), Conselho Nacional de Saúde. Resolução n. 196, de 10 de outubro de 1996; diretrizes e normas regulamentadoras de pesquisa envolvendo seres humanos. Brasília (DF), 1996.
8. Gaulejac V. Gestão como doença social: ideologia, poder gerencialista e fragmentação social. São Paulo: Ideias e Letras; 2007.

9. Trezza MC, Santos RM, Leite JL. Enfermagem como prática social: um exercício de reflexão. Rev. bras. enferm. [Internet] 2008;61(6) [acesso em 29 out 2013]. Disponível: http://dx.doi.org/10.1590/S0034-71672008000600019

10. Erdmann AL, Backes D, Alves A, Albino AT, Farias F, Guerini IC, et al. Formando empreendedores na enfermagem: promovendo competências e aptidões sócio-políticas. Enfermería Global. 2009;16:1-10.

11. Sarasvathy SD, Dew N, Velamuri SR, Venkataraman S. Three views of entrepreneurial opportunity. In: Acs ZJ, Audretsch DB. Handbook of entrepreneurship research: An interdisciplinary survey and introduction. $2^{\mathrm{a}} \mathrm{ed}$. New York: Springer; 2010. p. 77-96.

12. Lima RCD, Galavote HS, Schwartz TD, Ramos MC, Prado TN, Maciel ELN. Significando os sentidos da vida na formação dos profissionais de saúde: com a palavra os estudantes. Cogitare enferm. [Internet] 2011;16(1) [acesso em 29 out 2013]. Disponível: http://ojs.c3sl.ufpr. br/ojs2/index.php/cogitare/article/view/21129/13955

13. Filion LJ. Empreendedorismo e gerenciamento: processos distintos, porém complementares. RAE Light. [Internet] 2000;7(3) [acesso em 29 out 2013]. Disponível: http://dx.doi.org/10.1590/S0034-75902000000300013

14. Lelli LB, Bernardino E, Peres AM, Fabriz LA. Estratégias gerenciais para o desenvolvimento de competências em enfermagem em hospital de ensino. Cogitare enferm. [Internet] 2012;17(2) [acesso em 29 out 2013]. Disponível: http://ojs.c3sl.ufpr.br/ojs2/index. php/cogitare/article/view/24932/18480

15. Backes DS, Erdmann AL. Formação do enfermeiro pelo olhar do empreendedorismo social. Rev. Gaúcha Enferm. [Internet] 2009;30(2) [acesso em 29 out 2013]. Disponível: http://seer.ufrgs.br/ RevistaGauchadeEnfermagem/article/view/7252/6681

16. BastosMF, Ribeiro RF. Educaçãoeempreendedorismosocial: um encontro que (trans)forma cidadãos. Rev. Diálogo Educ. [Internet] 2011;11(33) [acesso em 29 out 2013]. Disponível: http://educa.fcc.org.br/pdf/de/v11n33/v11n33a16.pdf

17. Costa AM, Barros DF, Carvalho JLF. A dimensão histórica dos discursos acerca do empreendedor e do empreendedorismo. Rev. Adm. Contemp. [Internet] 2011;15(2) [acesso em 29 out 2013]. Disponível: http:// dx.doi.org/10.1590/S1415-65552011000200002 